\title{
Erratum to: Effect of seabed slope on the pile behaviour of a fixed offshore platform under lateral forces
}

\author{
K. Muthukkumaran · K. S. Arun
}

Received: 4 August 2014 / Accepted: 7 January 2015 / Published online: 29 April 2015

(C) Springer International Publishing AG 2015

\begin{abstract}
Fixed offshore platforms supported by pile foundations have to resist lateral loads due to wave and current forces. The response to environmental loads is strongly affected by the soil-structure (pile) interaction. Forces exerted by waves are the predominant lateral environmental forces governing jacket structure design, especially the foundation piles. The purpose of the present investigation is to perform a static wave analysis of a typical fixed offshore platform in extreme environmental conditions and to study the effects of the combined lateral and vertical loads on pile group foundations. The three-dimensional modelling and analysis of the offshore platform are carried out using the finite difference method. The present analysis is done under static conditions considering the structural and environmental loads at extreme environmental conditions, reaching the state of static equilibrium. A parametric study is done by varying the seabed slope to examine the differences in the soil-structure interaction behaviour of piles. The lateral displacement at the pile top and at the seabed level increases with the seabed slope. Also the depth at which the maximum shear force and bending moment occur from the pile top increases with the seabed slope.
\end{abstract}

This article has been published before under doi:10.1007/s40722-0150013-7. Unfortunately, it was an uncorrected version that should not be cited. For future citations, please refer to this corrected version under doi:10.1007/s40722-015-15.

The online version of the original article can be found under doi:10.1007/s40722-015-0013-7.

K. Muthukkumaran $(\varangle) \cdot$ K. S. Arun

Department of Civil Engineering, National Institute of Technology, Tiruchirappalli 620 015, India

e-mail: kmk@nitt.edu; kmk_iitm@yahoo.com
Keywords Fixed offshore platform · Soil-structure interaction · Static wave load · Finite difference analysis (FDA) · Lateral displacement · Bending moment

\section{Introduction}

Piles are subjected to significant lateral loads and overturning moments in addition to the axial load. Lateral loads are on the order of $10-15 \%$ of the vertical loads in the case of onshore structures, and in the case of coastal and offshore structures, these lateral loads can exceed $30 \%$ of the vertical loads (Narasimha Rao et al. 1998). Hence, the foundation piles have a significant effect on the response of fixed offshore structures due to lateral loading. Among all the environmental forces, wave forces and those due to ocean currents associated with waves contribute the most to the total lateral forces experienced by offshore structures. Therefore, proper attention has to be given to designing pile structures for fixed offshore platforms experiencing lateral loads.

Piles are commonly selected as a cost-effective option to support raised structures, highway infrastructures, and offshore platforms. These structural elements are often subjected to considerable lateral forces such as wind loads in hurricane-prone areas, earthquake loads in areas of seismic activity, and wave loads in offshore environments. Soilstructure interaction is the mechanism that governs the pile response behaviour and the ultimate capacity of the structure for the applied loads. A common approach to the analysis of laterally loaded piles is load transfer, which involves treating the soil as a series of springs down the length of the pile. Upon defining the deformational characteristics of the soil medium, the flexural behaviour of the foundation, and 
the conditions at the interface, the soil-foundation interaction problem is basically reduced to the determination of the contact stress distribution at the interface. Once the contact stresses have been determined, it is possible to evaluate the deflections, flexural moments, and shear forces in the foundation and the corresponding stresses and displacements in the soil medium.

An oil platform or rig is a large offshore structure used to house the workers and machinery needed to drill and/or produce oil and natural gas through wells in the ocean bed. Exploration drilling in shallow water depths is mostly facilitated by a fixed jacket platform, whereas floating structures are used for depths as deep as $2000 \mathrm{~m}$. Based on the geometry and characteristics, the offshore structures are classified into fixed platforms, compliant platforms, and floating production systems.

Pile foundations are very important in the study of fixed offshore structure responses. The response to environmental loads is strongly affected by soil-pile interactions. Among the environmental forces, wave forces and those due to ocean currents associated with waves contribute the most to the total lateral forces experienced by offshore structures. The deck also receives vertical loads due to crew quarters, drilling rigs, and production facilities, etc.

Sloped seabed surfaces are common offshore because of the irregularities that may form because of the actions of water. Even after the installation of an offshore structure, a seabed slope may form because of erosion or the actions of water. Therefore, the structure needs to be sufficiently safe even in sloped seabed conditions. It is therefore essential to study the variations in soil-structure interactions for cases of sloping and plane seabeds for offshore structures.

The deformation and stresses of an offshore concrete pile under combined structural and wave loading were analysed by Eicher et al. (2003) using the finite element method. A control model is analysed using a specific set of control data, then compared to succeeding models as the pile and loading parameters are changed. The loading parameters used to complete this study are the wave period $(T)$, wave height $(H)$, and incident wave angle $(\alpha)$. The pile strength parameters used to complete the study are the mean concrete strength and amount of steel reinforcement. The effect of different parameters on the response of a fixed offshore platform subjected to transient loading due to extreme wave and current loading was studied by Mostafa and Naggar (2004). The soil resistance to the pile movement is modelled using dynamic $p-y$ ( $p$-lateral load vs. $y$-lateral deflection) and $t-z$ (axial load vs. axial settlement) curves to account for soil nonlinearity and energy dissipation through radiation damping. $p$ and $z$ multipliers are used to account for the pilesoil-pile interaction in a simplified way. Chae et al. (2004) conducted several numerical studies performed with a three- dimensional finite element method (FEM). Model tests and a prototype test of laterally loaded short rigid piles and a pier foundation located near slopes were studied and the model test results compared with the measurements of field tests. Because of the slope effect, the lateral resistance of the pile decreased when closer to the crest of the slope. The effect of seabed instability on a fixed offshore structure was examined by Mostafa and Naggar (2006). In this study, seabed instability manifested in the movement of soil layers, exerting lateral forces that might cause large stresses on offshore foundations. Many researchers have also studied the influence of ground slope on laterally loaded pile behaviour (Muthukkumaran et al. 2008; Almas Begum and Muthukkumaran 2009; Muthukkumaran 2014).

From the literature review, it is clear that the study of fixed offshore platform responses to different load types has received much attention from many researchers and practicing engineers. However, few studies are found in the literature on fixed jacket platform responses to wave and current loading, including the soil-structure (pile) interaction and seabed slope effect. As fixed jacket platforms are the most common type used, it is in industrial and commercial interests for these platforms to have a long life without succumbing to the harsh environment in which they perform. Fixed jacket platforms are very accident prone. Accidents have occurred in the past in all four stages: during transportation, installation, operation, and removal. The probability of accidents can be reduced by proper design and analysis of the structure. To provide a more accurate and effective design for pile foundation systems for fixed jacket platforms under axial and lateral loads, a finite difference model using FLAC-3D is created and analysed. The wave loads acting on the structure are calculated using the corresponding environmental data and applied together with the structural load. A static analysis is done to apply both the vertical and lateral load together. A parametric study is also carried out by varying the seabed slope under similar loading conditions.

\section{Platform description}

In the present study, a fixed jacket offshore platform (the Kvitebjørn platform) located in the Norwegian section of the North Sea at a depth of about $190 \mathrm{~m}$ is considered. The foundation of the platform is a piled steel jacket with four legs, and each leg has four vertical steel pile groups. The structure above the mean sea level (MSL) is about $25 \mathrm{~m}$ and is the upper part of the structure. This upper part weighs approximately $73,000 \mathrm{kN}$. The lower part of the structure is about $45 \mathrm{~m}$ from the sea water level, and the weight of the lower 


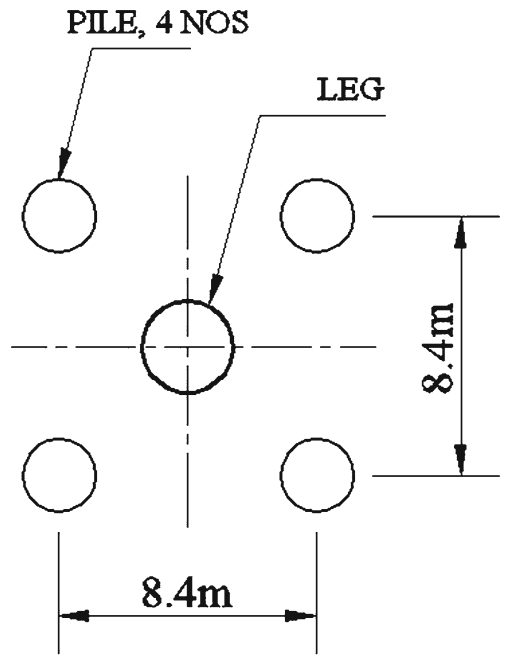

Fig. 1 Pile group layout for one leg, after Mostafa and Naggar (2004)

part is approximately $45,000 \mathrm{kN}$. The total structure is supported by 16 piles, and each pile has a depth and diameter of 90 and $2.438 \mathrm{~m}$, respectively. The weight of the foundation system is $53,000 \mathrm{kN}$. A levelling pile of $1.372 \mathrm{~m}$ diameter is used in each corner of the legs (Mostafa and Naggar (2004)). The structure below water level has $50 \times 50 \mathrm{~m}^{2}$ dimensions, whereas the top of the platform is $25 \times 25 \mathrm{~m}^{2}$. The top of the structure is approximately $\mathrm{El}-145$ to $\mathrm{El}+8 \mathrm{~m}$, with constant battering on all sides. The designed maximum operating topside weight of the structure is $225,000 \mathrm{kN}$ (Mostafa and Naggar (2004)). A typical pile group layout for one leg is shown in Fig. 1.

\section{Environmental data}

Environmental data for the Kvitebjørn platform were obtained according to STATOIL specifications, the 'Metocean Design Criteria'. The design's wave height and associated current speed for a 100-year return period are presented in Tables 1 and 2, respectively, as per Mostafa and Naggar (2004). Morison's equation (Morison 1950) is used to determine the wave forces. The marine growth (about $20 \mathrm{~mm}$ thick) effect is also considered in the wave force estimation.
Table 2 Values for associated current, after Mostafa and Naggar (2004)

\begin{tabular}{ll}
\hline $\begin{array}{l}\text { Depth below } \\
\text { sea level }(\mathrm{m})\end{array}$ & $\begin{array}{l}\text { Current speed } \\
(\mathrm{cm} / \mathrm{s})\end{array}$ \\
\hline 0 & 50 \\
25 & 50 \\
50 & 50 \\
75 & 46 \\
100 & 42 \\
125 & 39 \\
150 & 36 \\
175 & 32 \\
190 & 29 \\
\hline
\end{tabular}

Marine growth dry density is taken as $13 \mathrm{kN} / \mathrm{m}^{3}$, and the drag and inertia coefficients as 0.7 and 2.0, respectively. Using Stokes wave theory (Stokes 1847), the wave kinematics are calculated.

\section{Steps to determine wave loads}

Evaluation of the wave loads on a structure in the ocean involves the following:

1. Identification of 'normal' and 'extreme' loading conditions

2. Choice of a suitable wave theory

3. Evaluation of water particle velocities and accelerations according to the chosen theory, which in conjunction with Morison's equation (Morison et al. 1950) provides the quantitative evaluation of the force.

\subsection{Environmental considerations}

Consideration of normal environmental conditions (conditions expected to occur frequently during the life of the structure) is important during both the construction and service life of a platform, and consideration of extreme environmental conditions (conditions that occur quite rarely during the life of the structure) is important for formulating platform design loads. For extreme wave conditions, defining the extreme sea states should help determine the number, height, and crest elevations of all waves above a certain height that

Table 1 Design waves versus return period, after Mostafa and Naggar (2004)

\begin{tabular}{lllll}
\hline Return period (years) & $\begin{array}{l}\text { Wave height } \\
(H) \text { in meters }\end{array}$ & $\begin{array}{l}\text { Height above MSL } \\
(a) \text { in meters }\end{array}$ & \multicolumn{2}{l}{ Wave period } \\
\cline { 3 - 5 } & & & $\begin{array}{l}\text { Mean } \\
\text { value }(T)\end{array}$ & $90 \%$ Interval \\
\hline 1 & 22.5 & 12.8 & 13.8 & $12.2-15.5$ \\
10 & 25.3 & 14.2 & 14.6 & $13.0-16.4$ \\
100 (extreme conditions) & 28.5 & 16.1 & 15.3 & $13.6-17.1$ \\
10,000 & 36 & 20.4 & 17.1 & $15.1-19.1$ \\
\hline
\end{tabular}


might approach the platform site from any direction during the life of the structure. In this study, extreme environmental conditions are chosen for the analysis, i.e., the environmental data for a 100-year return period are considered. Accordingly, the extreme environment wave length is estimated. From the environmental data for extreme environmental conditions, and using the limits of validity for selected wave theory (Le Mehaute 1969), the region is found to be in the area of deep water waves. Therefore, Stokes wave theory (Stokes 1847) is used to calculate the water particle velocity and acceleration (wave kinematics).

Morison's equation (Morison et al. 1950) together with the API (2005) wave force guidelines is used to generate the wave forces. Since currents are associated with waves, due consideration is given to the possible superposition of currents and waves. Therefore, the current velocity added vectorally to the wave particle velocity before the total force is computed using Morison's equation (Morison et al. 1950). Using the above procedure, the total lateral loads due to waves and currents associated with the waves are calculated at different platform heights from the seabed to mean sea levels.

\section{Modelling of fixed jacket offshore platforms}

Numerical models involving the FDA can offer several approximations to predict true solutions. Often the problem being modelled is complex and has to be simplified to obtain a solution. Here finite difference analysis (FLAC-3D) is used. An explicit time-marching finite difference solution scheme is used for the analysis, and the calculation sequence is: (1) nodal forces are calculated from stresses, applied loads, and body forces; (2) the equations of motion are invoked to derive new nodal velocities and displacements; (3) element strain rates are derived from nodal velocities; (4) new stresses are derived from strain rates using the material constitutive law. This sequence is repeated at every time step, and the maximum out-of-balance force in the model is monitored. This force either approaches zero, indicating that the system is reaching an equilibrium state, or it approaches a constant, nonzero value, indicating that a portion (or all) of the system is at a steady-state (plastic) flow of material.

A multi-layered soil block is modelled using mesh brickshaped elements with eight reference points or nodes. Each structural element entity is composed of three components: nodes, individual elements (called SELs), and node/grid links. The characteristics of each component distinguish the behaviour of the beam, pile, and shell entities. The soil layers are modelled with the Mohr-Coulomb plastic model. Since the analysis was carried out using the Mohr-Coulomb soil model, the consolidation behaviour of the soil-on-pile response is not studied in this article. The soil profile considered is a multi-layered soil block. Poisson's ratio is taken as 0.25 for sand and 0.35 for clay. From the undrained cohesion $\left(c_{u}\right)$ and angle of internal friction $(\phi)$ values (Mostafa and Naggar 2004, 2006), Poisson's ratio, and the type of soil layer, the properties to be given as inputs for FLAC$3 \mathrm{D}$ are formulated (Table 3 ). These properties include the modulus of elasticity $(E)$, shear modulus $(G)$, bulk modulus $(K)$, angle of internal friction $(\phi)$, cohesion $(c)$, and shear strength.

The piles in each group are fixed to a rigid cap, which is modelled as a pile cap plate using shell elements, and the deck plate, modelled using shells, which is represented by threenode, flat, triangular elements. Each beam or pile element has two nodes and each node has 6 degrees of freedom ( 3 rotations and 3 translations at each node). Each element has 12 active degrees of freedom in total. Each shell element has 3 nodes and each node has 6 degrees of freedom, yielding a total of 18 degrees of freedom ( 3 rotations and 3 translations at each node) in the shell element. The stiffness matrix of the beam or pile element includes all six degrees of freedom at each node, representing the axial, shear, and bending action within a beam structure.

The soil and pile nodes are connected by bilinear MohrCoulomb interface elements. This allows an approximate representation of the development of lateral resistance with

Table 3 Soil properties formulated for FLAC 3D input after Mostafa and Naggar (2004, 2006)

\begin{tabular}{|c|c|c|c|c|c|c|c|c|}
\hline \multicolumn{3}{|c|}{ Soil layer data } & \multicolumn{6}{|c|}{ FLAC $3 D$ input } \\
\hline Sl. no. & Depth (m) & Type of soil & $E(\mathrm{kPa})$ & $G(\mathrm{kPa})$ & $K(\mathrm{kPa})$ & $\varphi(0)$ & $c(\mathrm{kPa})$ & $\begin{array}{l}\text { Shear strength } \\
(\mathrm{kPa})\end{array}$ \\
\hline 1 & 7.5 & Very soft to soft silty sandy clay & 3000 & 1111.11 & 3333 & 0 & 15 & 15 \\
\hline 2 & 24.5 & Sandy, clayey silt & 40,000 & $14,814.8$ & 44,444 & 0 & 80 & 80 \\
\hline 3 & 15 & Very stiff to hard silty clay & 180,000 & $66,666.7$ & 200,000 & 0 & 150 & 150 \\
\hline 4 & 5 & Very dense fine sand & 100,000 & 40,000 & 66,666 & 35 & - & 300 \\
\hline 5 & 10 & Very stiff to hard clay & 435,000 & 161,111 & 483,333 & 0 & 290 & 290 \\
\hline 6 & 15 & Very stiff to hard clay & 277,500 & 102,778 & 308,333 & 0 & 185 & 185 \\
\hline 7 & 8 & Very stiff to hard clay & 292,500 & 108,333 & 325,000 & 0 & 195 & 195 \\
\hline
\end{tabular}




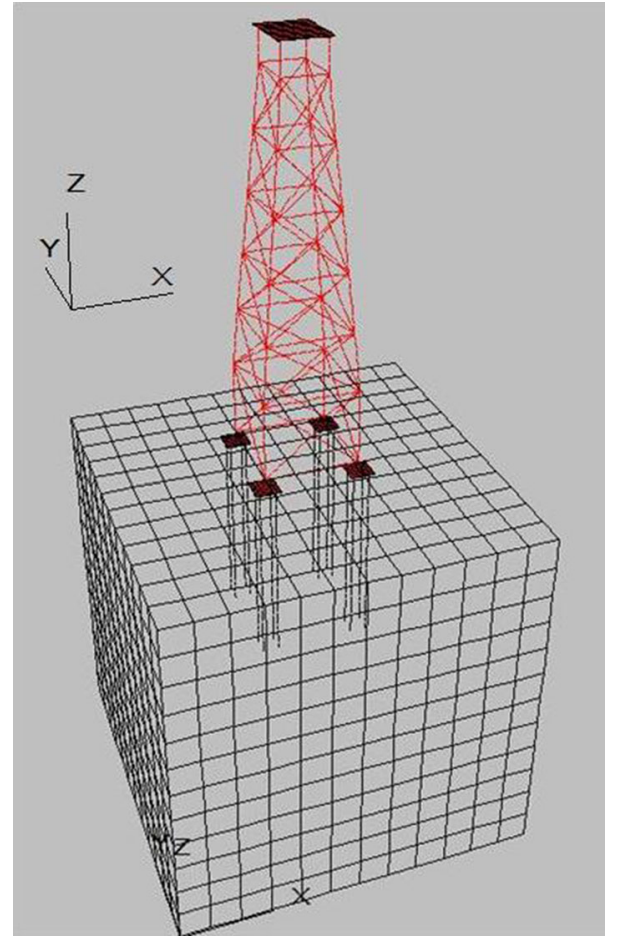

Fig. 2 Three-dimensional view of the generated finite difference model

the relative soil-pile movement and ultimately the full limiting soil pressure acting on the piles. Piles and the platform legs are assigned as pile and beam members, respectively, which are modelled as two-node structural element segments (material, steel; Young's modulus, $E: 2 \times 10^{11} \mathrm{~N} / \mathrm{m}^{2}$; Poisson's ratio, $v$ : 0.3 ; pile diameter, $d: 2.438 \mathrm{~m}$; pile length, $100 \mathrm{~m}$; embedded pile length, $90 \mathrm{~m}$ ). Horizontal elements and bracings are also modelled as beam parts. Two-node, linear elements represent the behaviour of beams and piles. Piles interact with the grid via shear and normal coupling springs. The coupling springs are nonlinear spring-slider connectors that transfer forces and motion between the pile and grid at the pile nodes (by the link emanating from each pile node). The spring constants are calculated using Vesic's equation (Vesic 1961).

The 3D view of the model generated is shown in Fig. 2. The top of the model at $z=0$ is a free surface. The base of the model at $z=500 \mathrm{~m}$ is fixed in the $z$ direction, and roller boundaries are imposed on the sides of the model at $x=150 \mathrm{~m}$ and $y=150 \mathrm{~m}$. In order to simulate the sloping ground in the model, the slope angle is introduced in the $x$ direction, which is against the lateral load. The model is first brought to an equilibrium stress state under gravitational loading before the installation of the piles. In case of sloping ground, the slope is introduced in the model before installation of the piles. In the next stage of analysis, the model is brought into equilibrium after installation of the piles.

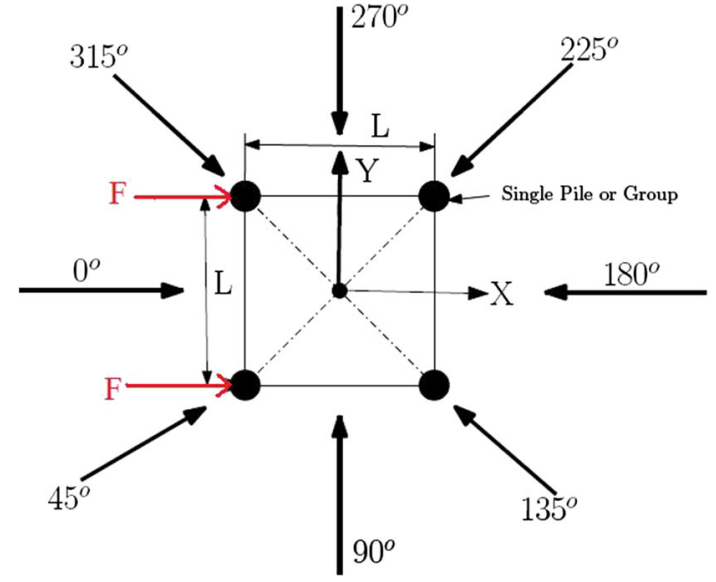

Fig. 3 Application of wave load (F) in the plan

\section{Application of loads}

The structural and the total wave loads are calculated for the extreme environmental conditions used for the static analysis. The total structural load intensity is estimated as $230,000 \mathrm{kN}$ (Mostafa and Naggar 2004). This load is applied as a vertical pressure on the top of the platform (deck plate), as shown in Fig. 4. The total lateral load $(F)$ caused by the waves and associated current is estimated as per the above theory, and it is assumed that the wave load acts in the $x$ direction, which is also against the seabed slope. The calculated forces are applied as equivalent static force (the hydrodynamic effect is not considered in the present analysis), as shown in Figs. 3 and 4. The maximum force is at the MSL and then reduces with water depth. Since the results are comparable with the results of Mostafa and Naggar (2004), even without considering the hydrodynamic aspect, the equivalent static analysis is sufficient to reduce the computational time.

\section{Static solution by finite difference analysis}

A certain number of steps are required to arrive at an equilibrium (or steady flow) state for a static solution. A static or steady-state solution is reached in the finite difference analysis when the rate of change of kinetic energy in a model approaches a negligible value. This is accomplished by damping the equations of motion. At the conclusion of the static solution stage, the model will be at either a state of equilibrium or a state of steady flow of material if a portion (or all) of the model is unstable (i.e., fails) under the applied loading conditions. A model is in exact equilibrium if the net nodal-force vector (the resultant force) at each grid point is zero. In the static analysis of a fixed offshore platform, the unbalanced force history reduces to a much lower value, and the displacement history at any node becomes constant, 
Fig. 4 Application of loads in elevation

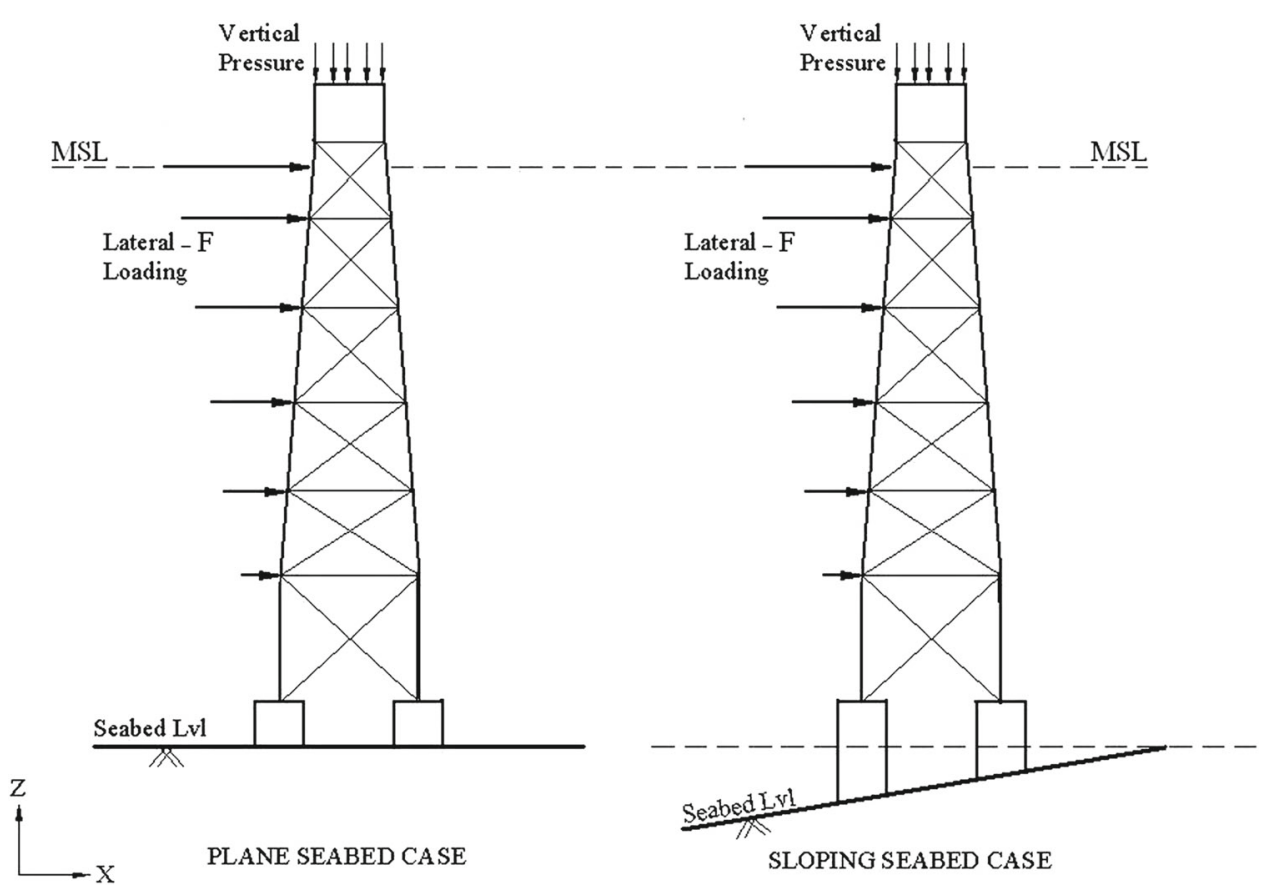

which indicates that the state of static equilibrium has been reached.

\section{Behaviour of piles on loading for plane seabed case}

The static analysis of the fixed offshore platform is done for the plane seabed case for the above-mentioned loadings, and the following results are obtained. The legend followed for the platform legs and piles in the group is shown in Fig. 5. For the response study, piles L1P2, L1P3, L2P2, and L2P3 are chosen, which are the front and rear piles of leg 1 (which is in tension) and leg 2 (which is in compression). According to the direction of loading ( $x$ direction as shown in Fig. 4.), the front and rear piles of legs are mentioned here. These four piles in a row in $x$ direction are chosen for the response study, since the other piles will also act symmetrically because of the same direction of lateral loading.

The four piles considered for the response study are:

\section{L1P2 Front pile of leg 1}

L1P3 Rear pile of leg 1

L2P2 Front pile of leg 2

L2P3 Rear pile of leg 2

\subsection{Validation of results}

The present FDA study results are compared with those of a similar study done by Mostafa and Naggar (2004). The lateral displacement and bending moment obtained for a pile

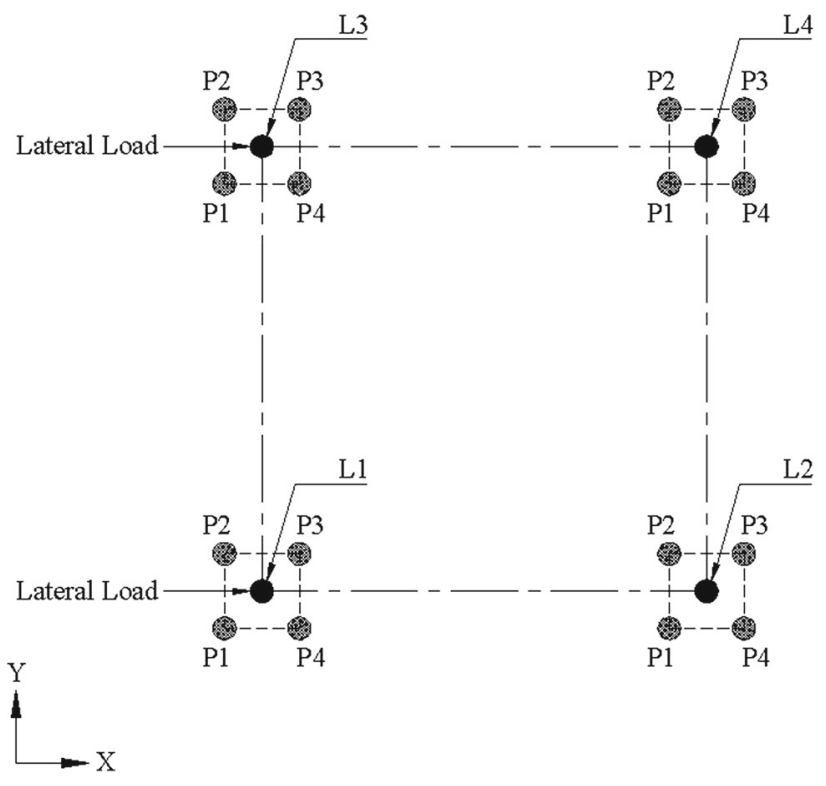

Fig. 5 Legend followed for platform legs and piles

are compared and shown in Figs. 6 and 7. From the comparison, the value of maximum displacement of the pile at the seabed surface and the bending moment obtained in the present study have very good agreement with the results of Mostafa and Naggar (2004). A mesh convergence (mesh sensitivity) analysis was also carried out for different mesh sizes including mesh refinement near the piles. However, there is no significant change in the result and hence the present mesh is used for further analysis with minimum computa- 


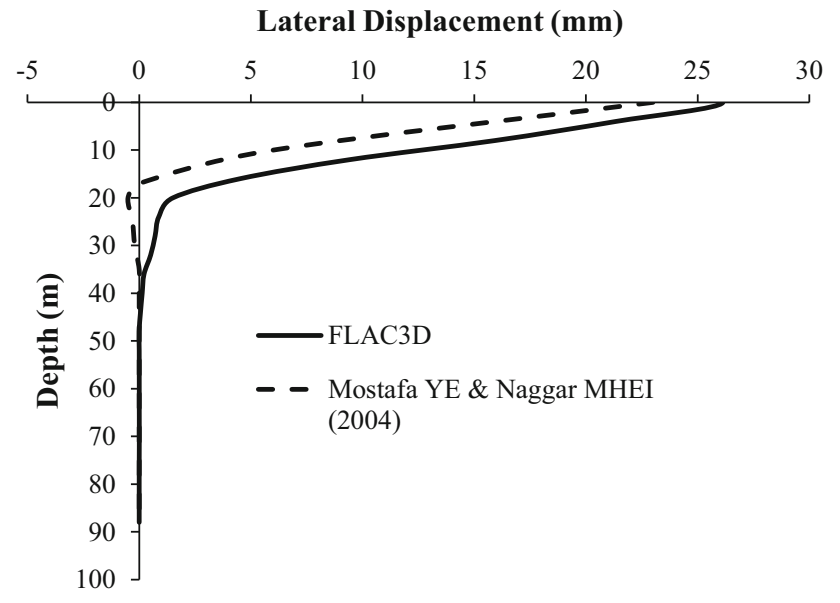

Fig. 6 Lateral displacement comparison

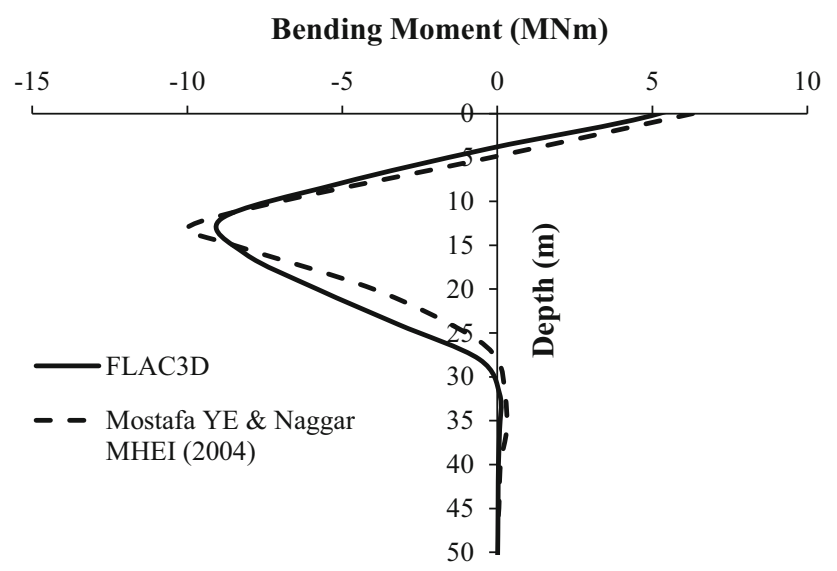

Fig. 7 Bending moment comparison

tional time. Also the mesh that shows comparable results to those of Mostafa and Naggar (2004) is used for further analysis.

\subsection{Comparison of the responses of piles in the group for plane seabed}

In order to understand the behaviour of legs and piles within the leg in the plane seabed, the lateral displacements of pile 2 and 3 of legs 1 and 2 were compared (Fig. 8). The zero value in the $y$-axis of these graphs shows the seabed level and the pile extends to $12 \mathrm{~m}$ above the seabed to the pile cap. From these graphs, the maximum values for the lateral displacement and bending moment can be compared for these piles in a row, in the direction of lateral load. The maximum lateral displacement at seabed level among all the piles occurs in the rear piles of leg 1 and leg 2 (i.e. L1P3 and L2P3). The maximum lateral displacement of L2P3 is $48 \mathrm{~mm}$, whereas for L1P3 it is $35 \mathrm{~mm}$. However, the front pile displacements of both legs (legs 1 and 2) are the same as for conditions
$28 \mathrm{~mm}$ under a plane seabed. This is because the moment developed because of the applied lateral load will be more at the top of the rear piles than the front piles. Also it is expected that the vertical load coming over the rear piles will be more than that on the front piles because of the lateral displacement of the piles. Therefore, the rear piles show more lateral displacement than the front piles in both legs.

Figure 9 shows the bending moment variation of piles in the legs. It is clearly seen that the maximum bending moment occurs in the same pile, L2P3, like in the lateral displacement. The influence of lateral load in the platform performance is significantly affected by the soil-pile interaction, which is clearly seen in the figure. The occurrence of the (depth of fixity) maximum bending moment below the seabed significantly changes from pile to pile in a leg or in the same piles in different legs. The depth of fixity of the rear pile in leg 1 and 2 is about 5.7 $\mathrm{D}$ and 6.4 $\mathrm{D}$ ( $\mathrm{D}$ is the diameter of the pile), respectively, where these values in the front piles of both the legs are almost the same at $3.7 \mathrm{D}$.

The rear pile bending moments are much higher than those in the front piles and also the depths of fixity of the rear pile are nearly two times more than in the front piles. This shows clearly that the stability of offshore platforms under these kinds of lateral load is critical; hence, the piles and structure need to be designed for critical conditions even though the pile sizes are the same.

\section{Parametric study introducing seabed slope}

The slope is introduced downwards, opposite to the direction of the lateral loading, and the downward slope is assumed to start from the top rear end point of the soil block with reference to the loading direction (i.e., along the $x$ direction). The introduction of the seabed slope is shown in Fig. 10. Generally, the offshore seabed has mild to steeper slopes with respect to the water depth and current forces. The seabed slope also depends on the nature of the seabed soils. In order to consider the seabed slope effect on the platform behaviour, the static analysis of the platform is done for different seabed slopes of 1 in 50,1 in 25, 1 in 10, and 1 in 5 under the same loadings. The analysis results were compared with a plane seabed slope, which clearly indicated the importance of the seabed slope in offshore platform behaviour. Since the geostatic stress and passive resistance in front of the pile are reduced in the sloped seabed case, there is a significant increase in the pile's lateral deflection and bending moment. In the present study, the effect of scour is considered in the pile response since the sloped seabed itself is subjected to lateral slinging. Therefore, the scour influence may not play a significant role in the pile response on sloped seabeds. 
Fig. 8 Lateral displacement vs. depth of piles with a plane seabed

Fig. 9 Bending moment vs. pile depth

9.1 Effect of seabed slope on lateral displacement

The lateral displacement versus depth of the L2P3, L2P2, L1P3, and L1P2 piles is shown in Figs. 11, 12, 13, and 14, respectively. From these figures, it is clear that the rear pile of
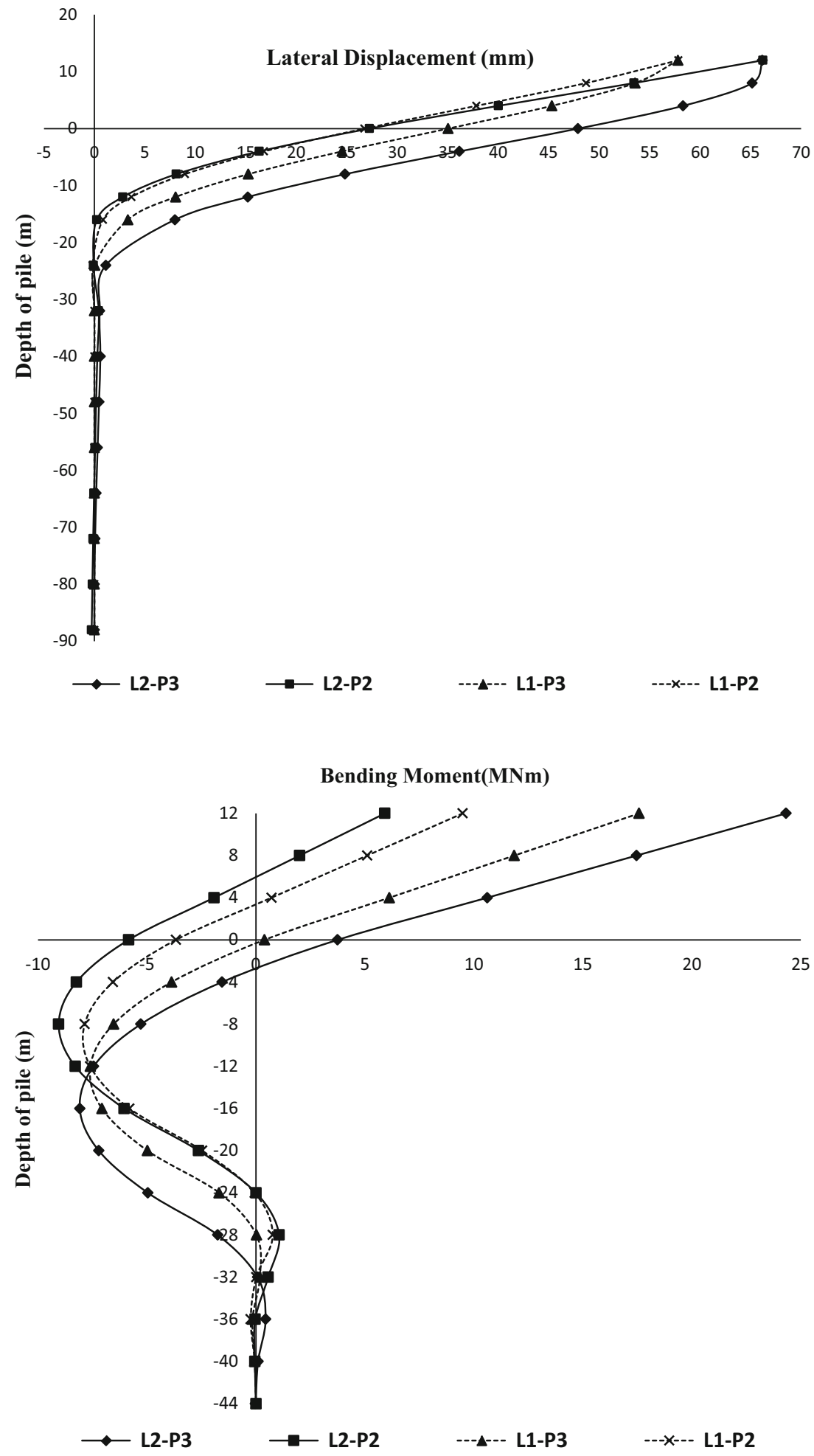

leg 2 shows the maximum lateral displacement in all sloped seabed conditions and that the lateral displacement of piles is not very significant up to a seabed slope of 1 in 10 . However, an increase in seabed slope beyond 1 in 10 has a very significant impact on the lateral response of the piles irre- 
Fig. 10 Diagram showing the direction of the slope introduced in the seabed

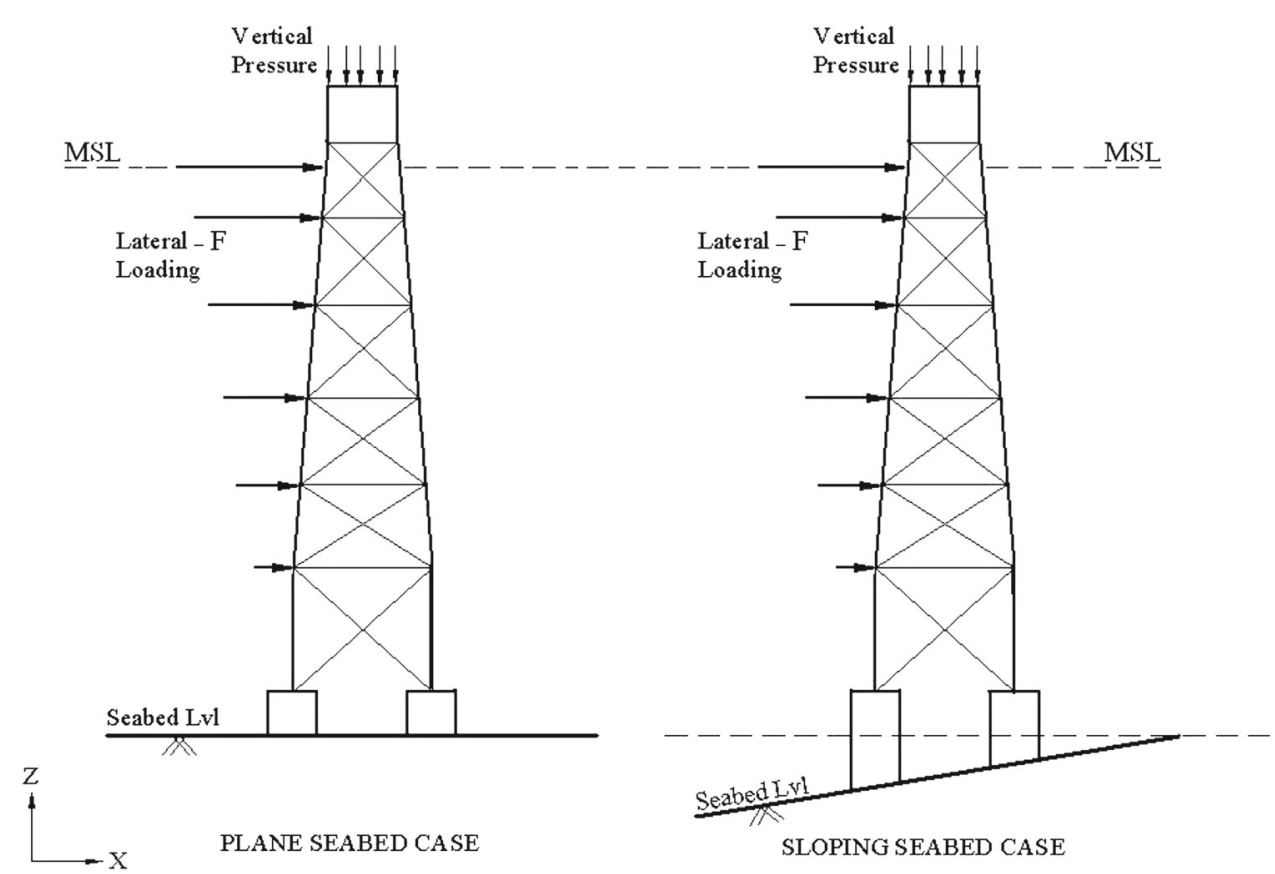

Fig. 11 Lateral displacement vs. pile depth (L2P3)

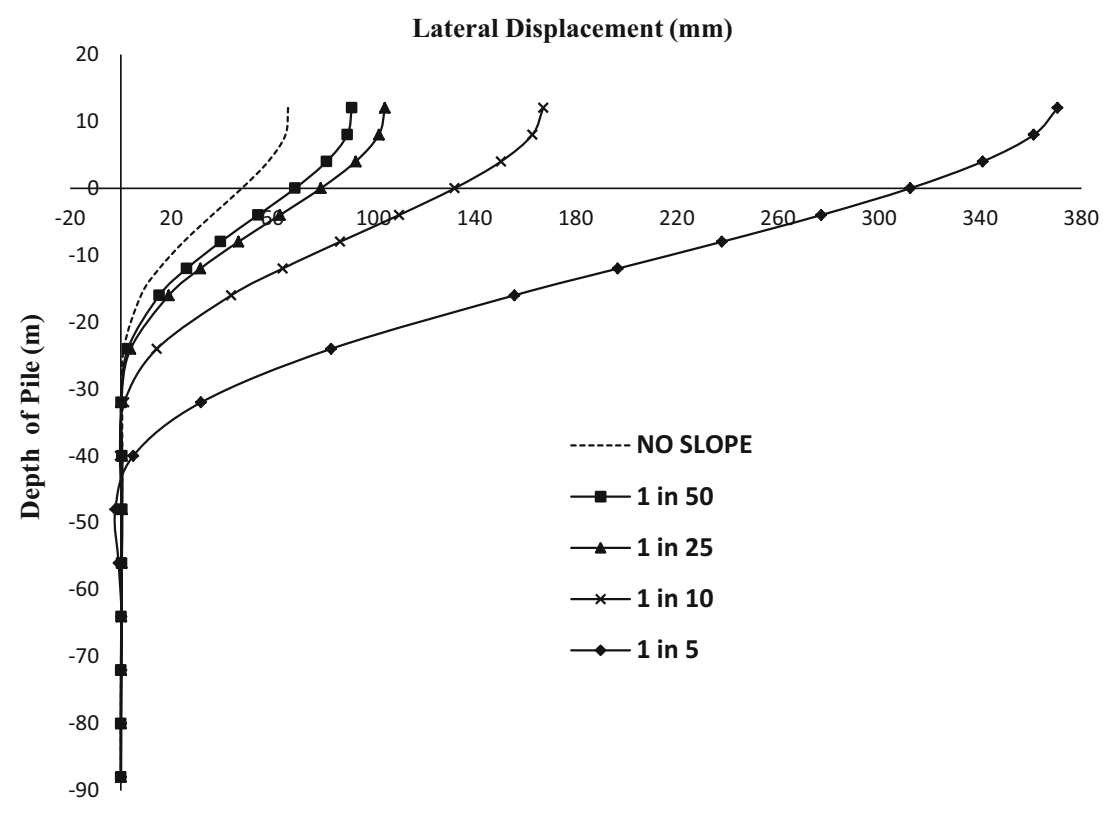

spective of the location (rear or front). The influence of the slope not only increases the lateral displacement, but also disturbs the overburden soil (top soil) more deeply than in the plane seabed condition. This is a very important observation for the axial capacity. Since the estimated axial capacity is also based on the side frictional resistance, there will be a significant reduction in the side friction. For instance, the lateral displacement is almost negligible at $28 \mathrm{~m}$ below the seabed level in the plane seabed, whereas it is nearly $42 \mathrm{~m}$ in the 1 in 50 seabed slope (Fig. 11).

Figure 15 shows the lateral displacement comparison with different seabed slopes. The lateral displacement of piles at the seabed level increases with an increase in the seabed slope. This is because the increase in seabed slope decreases the passive resistance mobilised in front of the pile and also the unstable slope leads to lateral sliding of the top soil towards the piles. Based on the analysis, it is clear that the L2P3 (leg 2, pile 3) pile is critical compared to the others. If we consider the behaviour of the L2P3 pile under various seabed slope conditions, the lateral displacement is nearly six times more in the 1 in 5 slope seabed than in the plane seabed. However, in the seabed slope up to 1 in 25 , the magnitude of lateral displacement is not very significant. From this observation, it can be concluded that if the seabed slope 
Fig. 12 Lateral displacement vs. pile depth (L2P2)

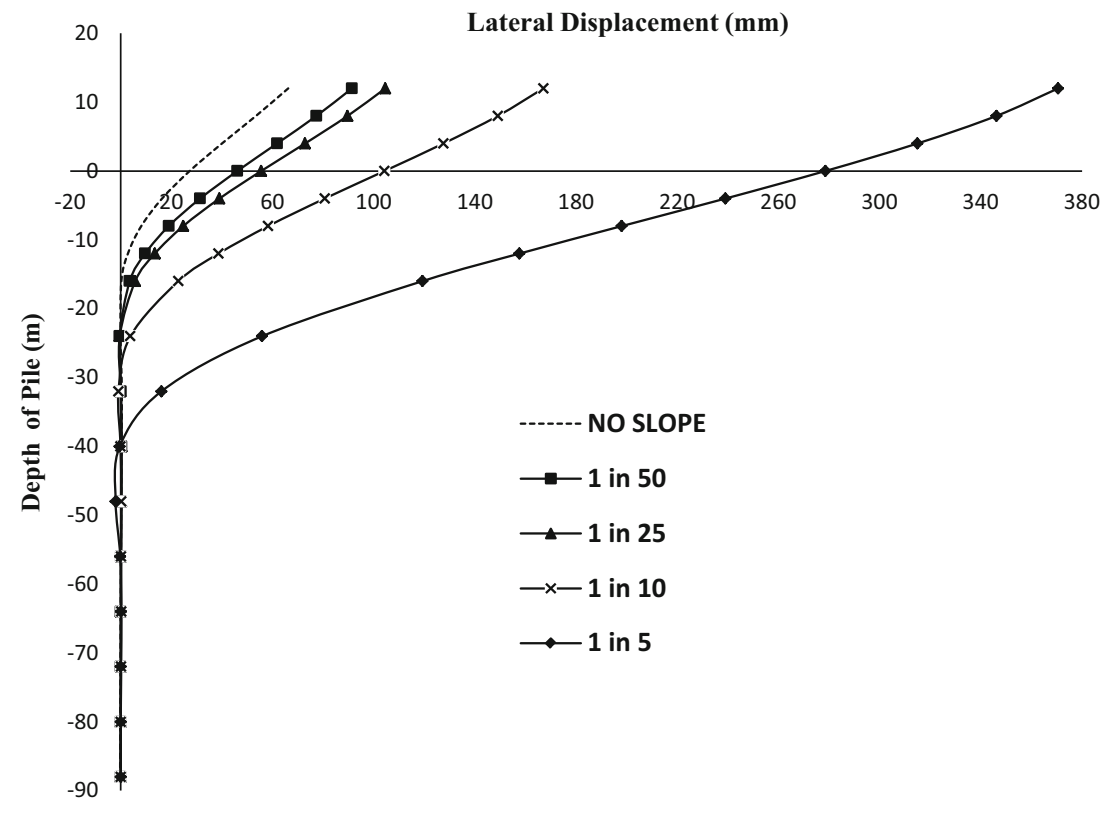

Fig. 13 Lateral displacement vs. pile depth (L1P3)

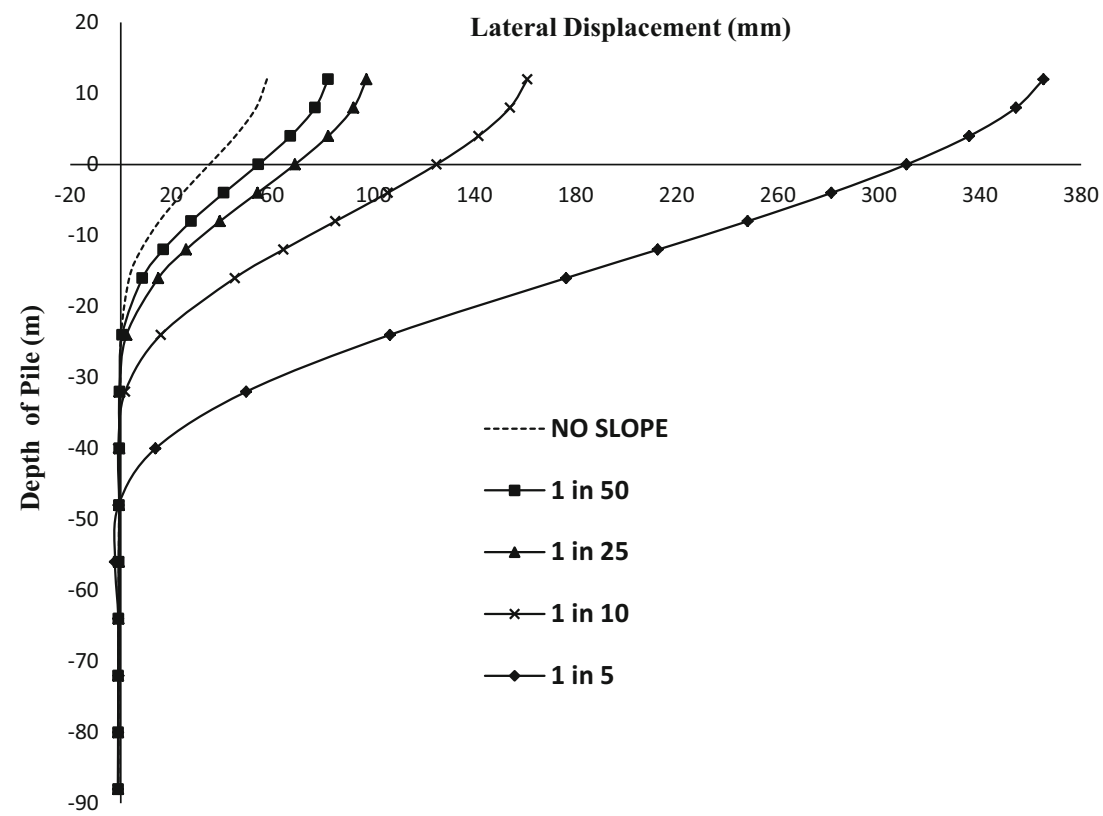

is flatter than 1 in 25 , the slope effect can be ignored, and there may not be any significant change in the offshore pile design. However, if the seabed slope is more than 1 in 25 (steepness), its effect needs to be considered in the offshore pile design, which is clearly shown in the lateral displacement diagram (Fig. 15). The sliding soil mass (in case of a steeper seabed slope) will generate high inertial and drag forces on the piles, which will significantly reduce the lateral as well as axial capacity of the piles. In the general pile design, this particular aspect may not always be considered, and this may be a critical aspect concerning offshore pile design in a sloped seabed.

\subsection{Effect of seabed slope on the bending moment}

In general, the piles were designed for the maximum bending moments. Normally, the fixed head piles will have two maximum moments, one at the pile top (i.e. the pile and pile cap connection) and the other some depth below the seabed or ground, which is normally called the depth of fixity. In general, the bending stress developed in the pile should be well within the allowable bending stress of the pile materials and this plays an important role in the pile's structural stability. In order to understand the bending behaviour of piles, the bending moment results are plotted against the depth of piles for 
Fig. 14 Lateral displacement vs. pile depth (L1P2)
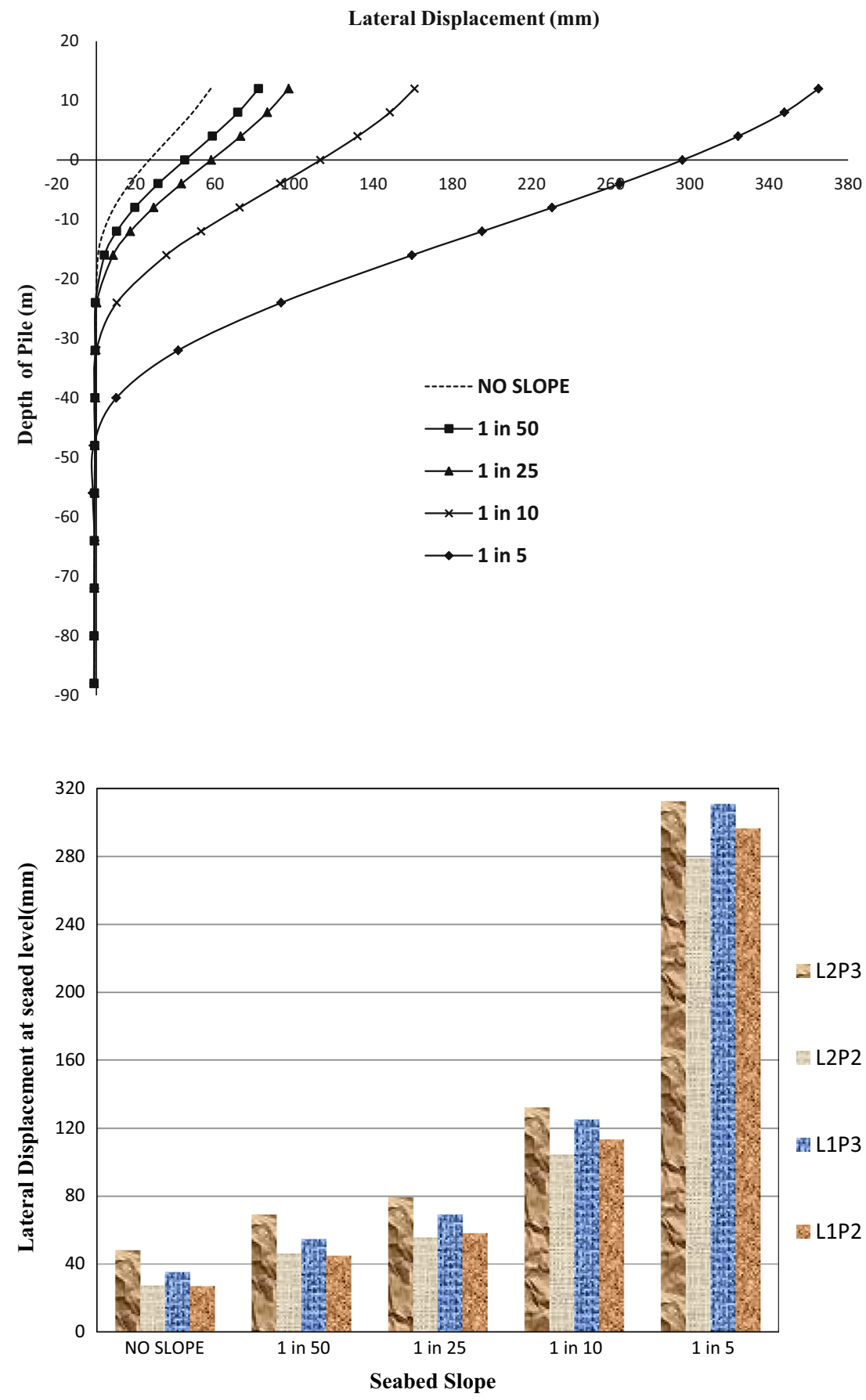

Fig. 15 Effect of seabed slope on lateral displacement of piles
L2P3, L2P2, L1P3, and L1P2, as shown in Figs. 16, 17, 18, and 19, respectively. These figures show that the seabed slope has a significant effect on the pile moment carrying capacity or moment of resistance, which is the direct measure of pile structural stability.

The seabed slope has a great influence on the pile head bending moment (the moment developing between the pile and pile cap joint) rather than the moments at the fixity depth, because the passive resistance reduction in the sloped seabed has a significant influence on the pile head moment as well as an additional lateral load due to lateral soil movement in steeper slopes. The seabed slope not only affects the moment carrying capacity of the piles, but also significantly influences the depth of fixity. As we know, in conventional pile designs, the piles are designed as a cantilever beam based on knowing the depth of fixity. If the seabed changes from a plane to a 1 in 5 slope, the depth of fixity is increased two fold in case of the L2P3 pile (Fig. 16). A similar kind of behaviour is observed in almost all of the piles. This shows that the developed moment may be very close to the moment of resistance of the pile, 
Fig. 16 Bending moment vs. pile depth (L2P3)
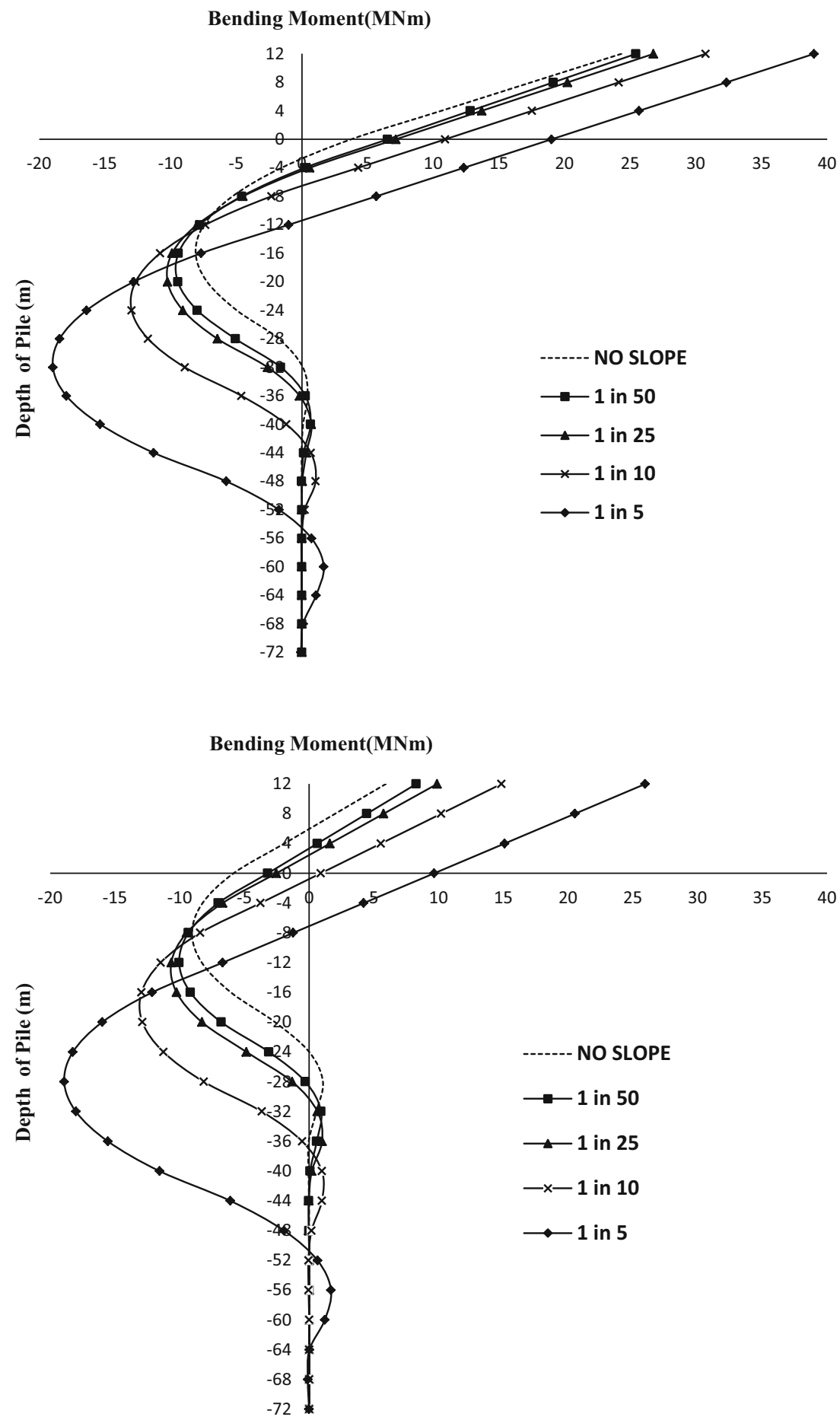

Fig. 17 Bending moment vs. pile depth (L2P2) or sometimes may be more than that, which finally leads to cracks in the pile members and affects the stability of the offshore platform.

Figure 20 shows a comparison of the maximum bending moments with different seabed slopes. The developed maximum bending moment increases with an increase in the seabed slope. The maximum bending moment variation is not significantly affected by the seabed slope in case of flat- ter slopes up to 1 in 10 , and beyond this seabed slope, the magnitude of the bending moment is significantly affected by the seabed slope. It is also observed that, when considering the influence of steeper slopes, the variation in the behaviour of the rear and front piles has been neglected. The magnitudes of L2P3 and L2P2 are almost the same, whereas there is a very slight variation in leg 1 for the steeper 1 in 5 seabed slopes. 
Fig. 18 Bending moment vs. pile depth (L1P3)
Fig. 19 Bending moment vs. pile depth (L1P2)
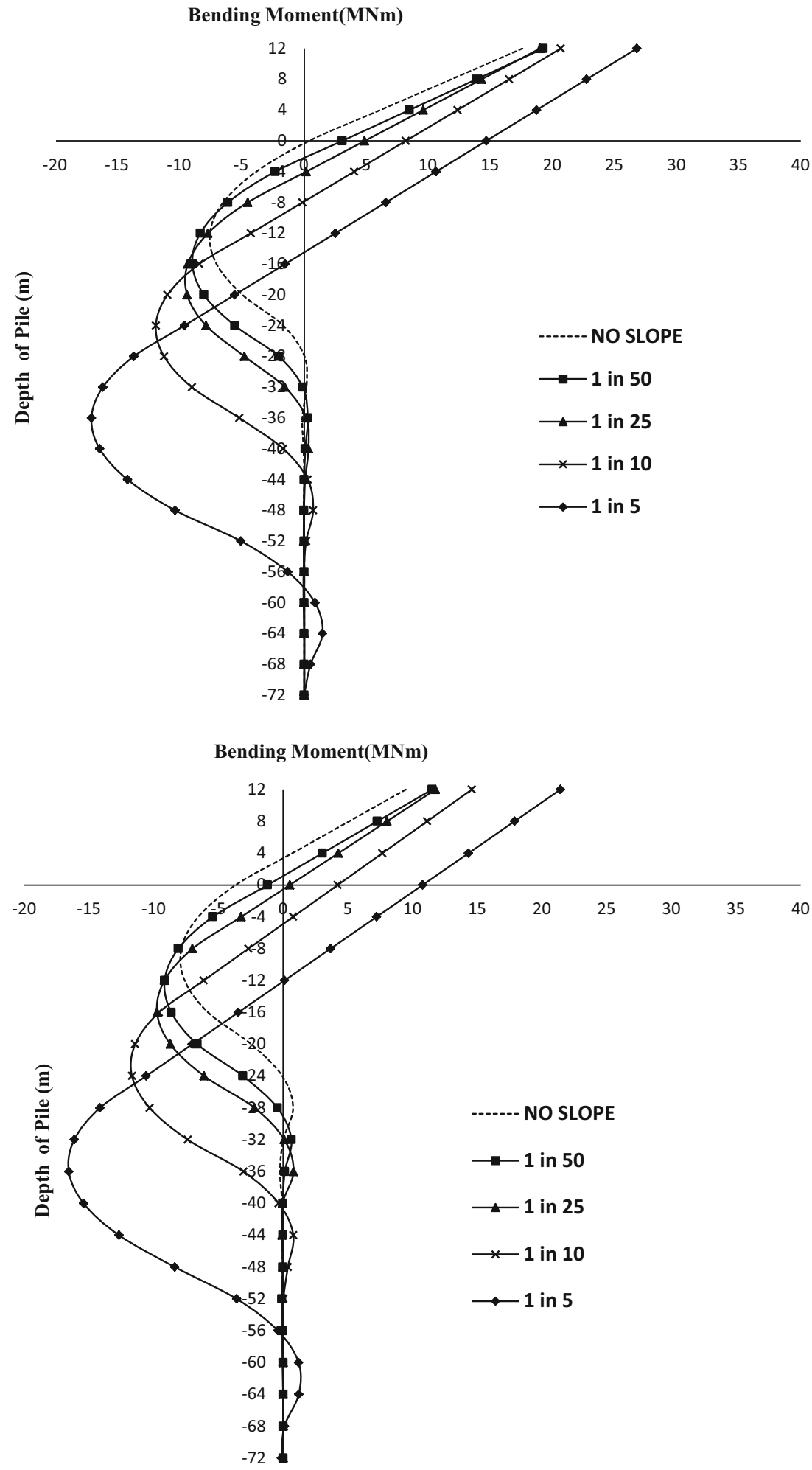

\section{Conclusions}

A three-dimensional finite difference model of the fixed jacket offshore platform has been modelled and satisfactorily validated according to Mostafa and Naggar (2004). From the analysis, it is clear that the seabed slope has a significant impact on offshore pile design in terms of the lateral displacement and bending moment. The following important conclusions are drawn based on the study: 
Fig. 20 Effect of seabed slope on the maximum bending moment of piles

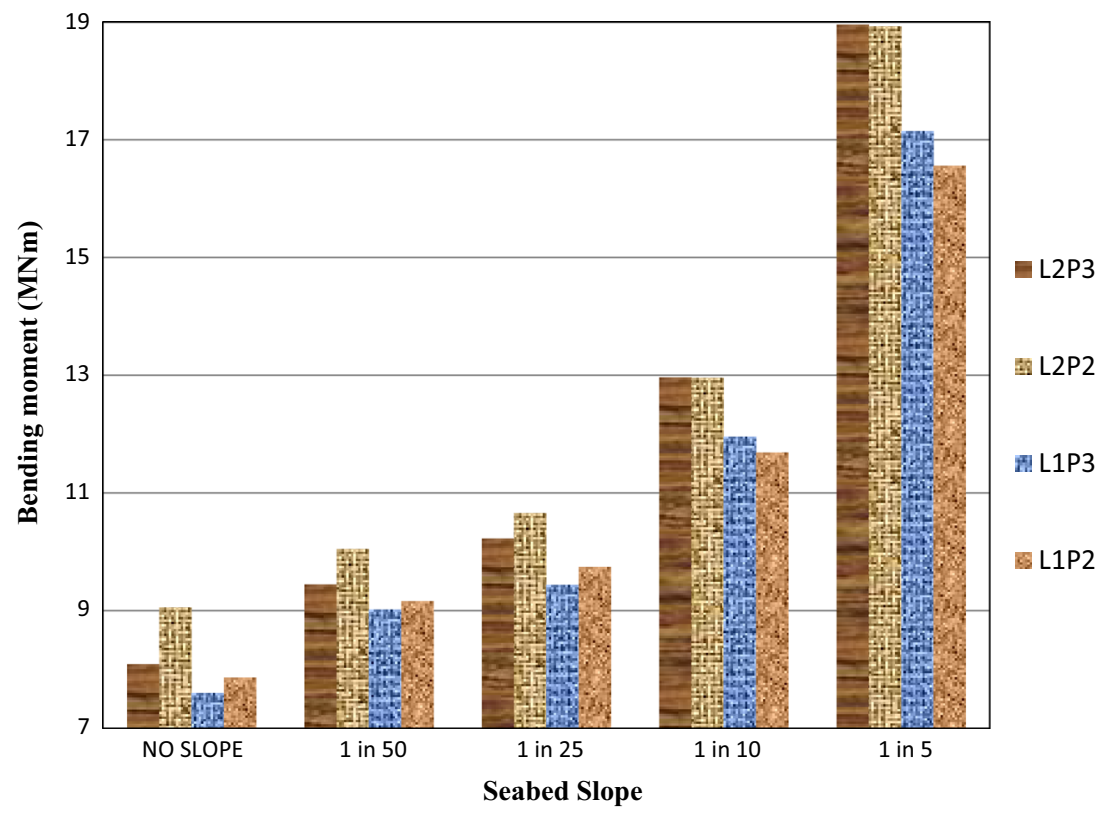

- From the analysis, it is concluded that, if the seabed slope is flatter than 1 in 20, the seabed slope may not have a significant influence on the pile behaviour and hence seabeds with a flatter slope may be treated as having plane seabed conditions and the pile design can be made accordingly.

- Steeper slopes (slope steeper than 1 in 10) not only influence the lateral pile behaviour, but also influence (reduce) the axial capacity since the top soil disturbance is increased in steeper slopes up to 40-45 m depth, whereas this is only at $25 ? 30 \mathrm{~m}$ depth in plane seabed conditions.

- In steeper seabed slopes ( 1 in 5 slope), the piles may be subjected to almost twice the bending moment of plane seabed conditions. This aspect needs to be considered in the offshore pile design in steeper seabed slopes.

- Steeper seabed slopes significantly influence the depth of fixity of the piles. The depth of fixity is almost twice that of plane seabeds in steeper 1 in 5 slopes. Consequently, the magnitude of the maximum bending moment is also twice as high.

- The analysis shows that for the steeper slopes (1 in 5 slopes) the variation in rear and front pile behaviours has been neglected. The magnitudes of L2P3 and L2P2 are almost the same in the steeper slopes, whereas there is significant variation in plane seabed conditions. Therefore, it is concluded that this particular aspect needs to be considered in the offshore pile design.

Acknowledgments Funding for this study was provided by the Department of Science and Technology (DST) under the Fast Track for Young Scientists Programme (SR/FTP/ETA-08/2007), and this support is gratefully acknowledged.

\section{References}

Almas Begum N, Muthukkumaran K (2009) Experimental investigation on single model pile in sloping ground under lateral load. Int $\mathbf{J}$ Geotech Eng 3(1):133-146

API (2005) Recommended practice for planning, designing and constructing fixed offshore platforms-working stress design, 21st edn. American Petroleum Institute Recommended practice 2AWSD, Washington, DC

Chae KS, Ugai K, Wakai A (2004) Lateral resistance of short single piles and pile groups located near slopes. Int J Geomech ASCE 4(2):93-103

Eicher JA, Guan H, Jeng DS (2003) Stress and deformation of offshore piles under structural and wave loading. J Ocean Eng 30:369-385

Le Mehaute B (1969) An introduction to hydrodynamics and water waves. Water wave theories, vol. 2. Essa Technical report ERL 118POL-3-2. U.S. Dept. of Commerce, Environmental Science Services Administration, Pacific Oceanographic Laboratories, Miami, FL

Morison JR, O'Brien MP, Johnson JW, Schaaf SA (1950) The force exerted by surface waves on piles. Pet Trans AIME 189:149-154

Mostafa YE, El Naggar MH (2004) Response of fixed offshore platforms to wave and current loading including soil-structure interaction. Soil Dyn Earthq Eng 24:357-368

Mostafa YE, El Naggar MH (2006) Effect of seabed instability on fixed offshore platforms. Soil Dyn Earthq Eng 26:1127-1142

Muthukkumaran K, Sundaravadivelu R, Gandhi SR (2008) Effect of slope on P-Y curves due to surcharge load. Soils Found 48(3):361365

Muthukkumaran K (2014) Effect of slope and loading direction on laterally loaded piles in cohesionless soil. Int J Geomech ASCE 14(1):1-7

Narasimha Rao S, Ramakrishna VGST, Babu Rao M (1998) Influence of rigidity on laterally loaded pile groups in marine clay. J Geotech Geoenviron Eng ACSE 124(6):542-549

Stokes GG (1847) On the theory of oscillatory waves. Trans Camb Philos Soc 8:441-455

Vesic AS (1961) Beams on elastic subgrade and the Winkler's hypothesis. In: 5th ICSMFE, vol 1, pp 845-850 